\title{
COVID-19 ¿Cómo disminuir el riesgo del endoscopista?
}

\author{
Enrique Murcio-Pérez* \\ Departamento de Endoscopia, Hospital de Especialidades Centro Médico Nacional Siglo XXI, Ciudad de México, México
}

El 30 de enero del 2020, la Organización Mundial de la Salud declaró una emergencia de importancia internacional debido al surgimiento de un nuevo coronavirus en China. El virus fue posteriormente llamado SARS-CoV-2 y la enfermedad resultante COVID-19 ${ }^{1}$. La transmisión del virus ocurre mediante pequeñas partículas líquidas expulsadas por una persona infectada por la boca o nariz al toser, hablar o estornudar. Fragmentos del virus se han encontrado también en la materia fecal de personas infectadas ${ }^{2}$. De tal forma que el SARS-CoV-2 es potencialmente transmisible durante endoscopia debido a que los procedimientos endoscópicos generan aerosoles y microgotas.

Un estudio presentado en la DDW 2021 y realizado en Japón por Ishida, et al. tuvo como objetivo evaluar la ocurrencia de fugas de aire en los sistemas de inserción de accesorios endoscópicos, así como la relación entre el grado de fuga y la presión de insuflación. Utilizaron el método de estrioscopia, el cual es un proceso óptico que permite visualizar la variación de densidad de un fluido y en este caso, permitió visualizar la fuga a través del canal de trabajo del endoscopio al introducir un accesorio. Los experimentos se realizaron en estómagos de modelos porcinos. En un primer tiempo, con el gastroscopio en el estómago se introducía y retiraba una pinza de biopsia a una velocidad aproximada de $3 \mathrm{~cm}$ por cada 3 segundos. Durante la movilización se observó fuga de aire al momento de la inserción y retirada de la pinza de biopsia en todos los casos, siendo esta de mayor grado cuando las válvulas presentaban desgaste o deterioro (uso por más de 10 veces). Posteriormente realizaron mediciones de la fuga cuando el estómago tenía presiones de 4 a $15 \mathrm{mmHg}$ observando una mayor velocidad de difusión de gas (fuga) a mayor presión intragástrica. Por lo tanto, los autores recomiendan utilizar presiones intragástricas menores y evitar el uso de válvulas deterioradas para evitar la posibilidad de fuga y disminuir la exposición a aerosoles ${ }^{3}$.

Dado que el riesgo teórico de transmisión del SARSCoV-2 durante una endoscopia existe, Hajifathalina, et al. presentaron en la DDW 2021 un estudio de cohorte en Nueva York de pacientes sometidos a endoscopia evaluando la incidencia de COVID-19 posterior al procedimiento endoscópico ${ }^{4}$. Fueron incluidos 1,222 pacientes ( $51 \%$ ambulatorio y $49 \%$ hospitalizados) de los cuales 78 (6.38\%) desarrollaron COVID-19 después de la endoscopia con una mediana de 23 días (rango intercuartílico: 11-42 días). La tasa de conversión fue significativamente menor después de la implementación del uso obligatorio de mascarilla (2.2\%).

Los resultados anteriores hacen pensar si la implementación de pruebas de tamizaje puede ser útil para disminuir el riesgo de COVID-19. Noorali, et al. mostraron los resultados de la utilidad del tamizaje preendoscópico con prueba rápida de anticuerpos para COVID-19 en pacientes a quienes se les iba a realizar estudio endoscópico electivo ambulatorio. A todos los pacientes les era solicitado llenar un cuestionario y se les tomaba la temperatura. En caso de síntomas no se programaba el estudio y se enviaba a realización de PCR. Solo aquellos pacientes sin síntomas respiratorios, sin fiebre, sin síntomas gastrointestinales agudos o exposición conocida a COVID-19 eran programados. En las instalaciones del servicio de endoscopia, todos (pacientes y personal) utilizaban mascarilla. Además,

\section{Correspondencia:}


las instalaciones del servicio contaban con un sistema especializado de filtración de aire. Un total de 33 pacientes $(0.94 \%)$ fueron positivos a la prueba rápida de anticuerpos. Siete $(0.2 \%)$ eran por exposición previa (anticuerpos $\lg G$ ) mientras que $26(0.7 \%$ ) fueron $\lg M o$ IgM/IgG positivo. A los pacientes con IgM positiva se les realizó prueba PCR y no se les practicó endoscopia, dado el riesgo de transmisibilidad del virus, siendo positiva en el $43 \%$. Ningún miembro del staff de endoscopia fue diagnosticado de COVID-19 durante el tiempo del estudio 5 .

Los estudios recientemente presentados en la DDW refuerzan mensajes importantes para el endoscopista durante la pandemia por COVID-19. El primero es que el riesgo de transmisión en la endoscopia existe y está bien fundamentado al ocurrir fuga de aire durante la manipulación de instrumentos. Segundo, las pruebas rápidas de anticuerpos en población de bajo riesgo (sin fiebre, sin síntomas) que va a ser sometida a un procedimiento de endoscopia tiene un rendimiento bajo $(<1 \%)$. Y el tercero y más importante es que el uso de equipo de protección (particularmente la mascarilla de alta eficiencia) es una estrategia efectiva disminuye el riesgo de COVID-19 para pacientes y personal. En Italia, uno de los epicentros durante el inicio de la pandemia en Europa, observaron que el $85.7 \%$ de los casos de COVID-19 en trabajadores relacionados a la salud ocurrieron antes de la implementación sistemática de medidas de seguridad (selección de casos, uso de equipo de protección personal) ${ }^{6}$. Un estudio previo realizado en nuestro medio mostró que el apego a uso de mascarilla de alta eficiencia durante el procedimiento es adecuado, siendo realizado en el $97 \%$ de los endoscopistas de México y Latinoamérica ${ }^{7}$. En conclusión, los endoscopistas debemos continuar seleccionando, interrogando y utilizando medidas de protección personal con mascarilla de alta eficiencia para disminuir el riesgo de COVID-19.

\section{Financiamiento}

La presente investigación no ha recibido ayudas específicas provenientes de agencias del sector público, sector comercial o entidades sin ánimo de lucro.

\section{Conflicto de intereses}

Los autores declaran no tener conflicto de intereses.

\section{Bibliografía}

1. Coronaviridae Study Group of the International Committee on Taxonomy of Viruses. The species severe acute respiratory syndrome-related coronavirus: classifying 2019-nCoV and naming it SARS-CoV-2. Nat Microbiol. 2020;5:536-44.

2. Xiao F, Tang M, Zheng X, Liu Y, Li X, Shan H. Evidence for gastrointestinal infection of SARS-CoV-2. Gastroenterology. 2020;158:1831-3.

3. Ishida T, Naka K, Fujimoto K, Yamashata K, Saito T, Tanaka K, et al. Sa115 Gas leaks from biopsy valves of gastrointestinal endoscopy. Its visualization and semi-quantification utilizing Schlieren optical system. Gastroenterology [Internet]. 2021;93(6 Suppl):S426-S427. Disponible en: https://www.gastrojournal.org/article/S0016-5085(21)01728-5/fulltext

4. Hajifathalian K, Sharaiha T, Safford M. et al. Conversion rate for COVID-19 in New York. City: Impact of social distancing and universal masking. Sesión de carteles electrónicos presentada en DDW; 2021. Mayo. 29-31: Sa111.

5. Noorali A, Yohida K, Stephens J, Parrish RA, Sedghi S. Fr094 Utility of COVID-19 antibody testing for pre-endoscopy screening. Noorali A, Yoshida K, Stephens J, Parrish RA, Sedghi S. Gastroenterology [Internet]. 2021;160(6):S216. doi:10.1016/S0016-5085(21)01257-9

6. Repici A, Aragona G, Cengia G, Cantù P, Spadaccini M, Maselli R, et al. Low risk of COVID-19 transmission in Gl endoscopy. Gut. 2020;69:1925-7.

7. Murcio-Pérez E, Zamarripa-Mottu RA, Andrade-dePaulo G, Aguilar-Nájera O, Asadur Tchekmedyian J, Blanco-Velasco G, et al. Adherence to recommendations for endoscopy practice during COVID-19 pandemic in Latin America: how are we doing it? BMJ Open Gastroenterol. 2021;8:e000558. 